\title{
Comparison of Levofloxacin-Based, 10-day Sequential Therapy with 14-day Quadruple Therapy for Helicobacter Pylori Eradication: A Randomized Clinical Trial
}

\author{
Eskandar Hajiani ${ }^{1}$, Pezhman Alavinejad ${ }^{1,}$, Nahid Avandi ${ }^{2}$, \\ Abdol Rahim Masjedizadeh ${ }^{1}$, Ali Akbar Shayesteh ${ }^{1}$
}

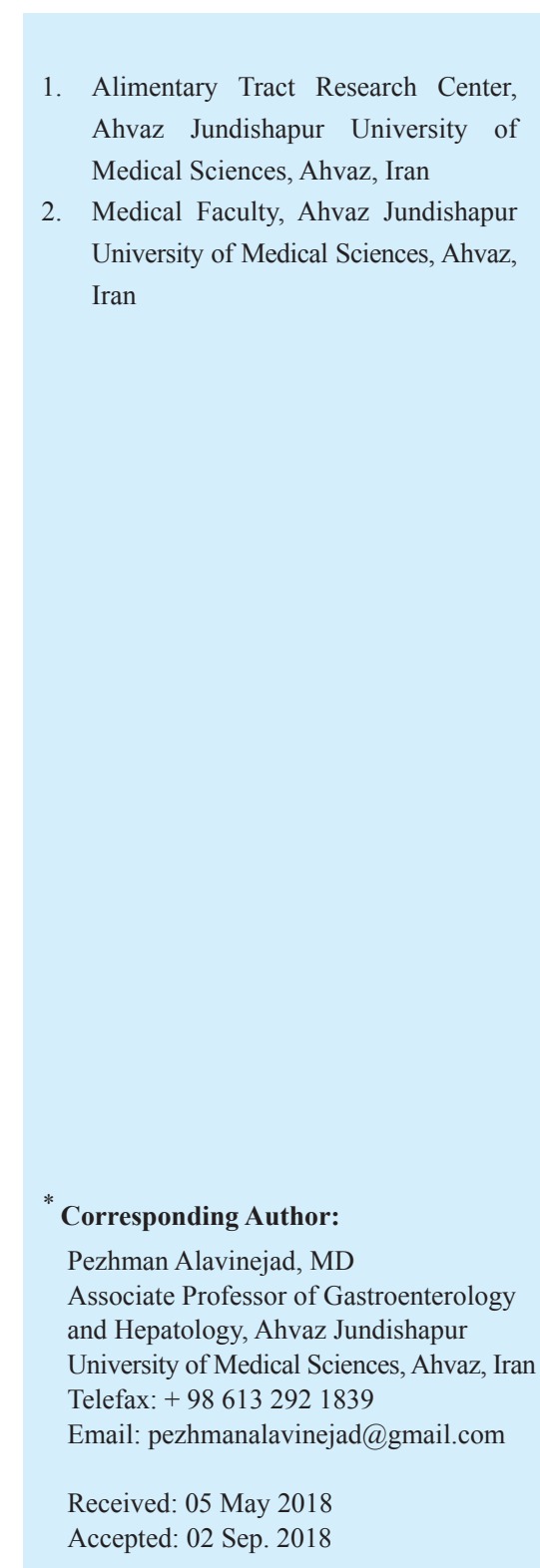

\section{ABSTRACT}

\section{BACKGROUND}

Considering the importance of Helicobacter pylori (H. pylori) eradication, this clinical trial was designed to prospectively evaluate the efficacy of levofloxacin-based, sequential therapy in comparison with quadruple therapy for eradicating H. pylori.

\section{METHODS}

Overall 156 patients with dyspepsia and $H$. pylori infection were included in this study and were randomly allocated to either 10-day sequential therapy group (group A) to receive pantoprazole (40 mg twice daily), amoxicillin (1 gr twice daily), levofloxacin (500 $\mathrm{mg}$ twice daily), and tinidazole (500 mg twice daily) (PALT) or 14-day quadruple therapy group (group B) to receive pantoprazole, clarithromycin, bismuth subcitrate, and amoxicillin (PABC). At the end of the study the eradication rate in each group was assessed by urea breath test (UBT).

\section{RESULTS}

Age range of the participants was $18-65$ years (average 36.9 years) and $50 \%$ of them ( 78 patients) were men. 78 patients were allocated to group A and 78 patients to groupe B. After antibiotic therapy, all the patients received acid suppression therapy with Proton Pump Inhibitor (PPI) for 4 weeks and then the eradication rate was confirmed by UBT (Heli FAN plus 13C, Germany). Before performing UBT, all the participants were requested to halt consumption of PPI for at least 1 week. During the treatment there was not any major complication but in group A (sequential therapy), two patients complained of minor complications including musculoskeletal pain. None of the patients in group B had any complaint or side effect.

The rate of H. pylori eradication in group A was 78.2\% (61 patients) while this rate in group B was $83.3 \%$ ( 65 patients) with no significant difference between the two groups $(p=0.42)$. In subgroup analysis, the rate of eradication among men in group A and B were $76.9 \%$ and $89.7 \%$, respectively $(p=0.22)$ while the eradication rate among women were $79.4 \%$ and $76.9 \%$, respectively $(p=1.00)$.

\section{CONCLUSION}

It seems that levofloxacin base sequential therapy does not have any advantage in comparison with quadruple regimen and until finding any more effective short course therapy for $\mathrm{H}$. Pylori eradication; we encourage quadruple regimen to be used as the first line therapy.

\section{KEYWORDS:}

H. Pylori, Eradication, Sequential therapy, Levofloxacin

Please cite this paper as:

Hajiani E, Alavinejad P, Avandi N, Masjedizadeh AR, Shayesteh AA. Comparison of Levofloxacin-Based, 10-day Sequential Therapy with 14-day Quadruple Therapy for Helicobacter Pylori Eradication: A Randomized Clinical Trial. Middle East J Dig Dis 2018;10:242-248. doi: 10.15171/mejdd.2018.117.

\section{INTRODUCTION}

Helicobacter pylori $(H$. pylori) plays an important role in the pathogenesis of chronic active gastritis, peptic ulcer disease, low-grade mucosa associated 
lymphoid tissue (MALT)-lymphoma, and gastric cancer development. ${ }^{1-6}$ Current recommended $H$. pylori treatment regimens generally include triple therapy based on two antibiotics such as amoxicillin- clarithromycin or amoxicillin-metronidazole and a Proton Pump Inhibitor (PPI) triple therapies for 10 to 14 days. ${ }^{7-9}$ However, the efficacy of these therapies is decreasing worldwide, mostly because of an increased prevalence of antibiotics and specially clarithromycin resistance. ${ }^{10-12}$ Moreover, there is some evidence that the success rate of the triple therapies in clinical practice is usually more than $10 \%$ lower compared with the eradication rates observed during clinical trials. ${ }^{13}$

About 10 years ago, a novel therapeutic regimen called "sequential regimen" was proven highly effective (cure rate $>90 \%$ ) in several Italian trials ${ }^{14}$ and after confirmation in clinical trials, this method was recommended by several guidelines. ${ }^{15-22}$ Several rescue therapies have been recommended after failure of the first attempt to eradicate $H$. pylori but they still have failure rate of more than $20 \% .{ }^{20,23-26}$ Levofloxacin-based therapies seem to be effective as an effective regimen for eradicating $H$. pylori but a standard pattern of levofloxacin-based therapy is still lacking. ${ }^{27-30}$

In Iran, primary bacterial resistance to metronidazole, clarithromycin, amoxicillin, and levofloxacin is about $37.5 \%$ to $78.6 \%, 28 \%$ to $34 \%, 10 \%$, and $5.3 \%$, respectively. ${ }^{31-37}$ Levofloxacin provides an excellent alternative to combined therapy for $H$. pylori eradication as a substitute for amoxicillin or metronidazole, resulting in good eradication rates in patients who have had failed treatment. However, its use has not become widespread because of the reported side effects. ${ }^{30,38,39}$ The aim of this study was to prospectively evaluate the patients receving a levofloxacin-based, sequential treatment in order to assess the effectiveness and safety of this therapeutic approach in obtaining successful eradication and compare it with quadruple therapy.

\section{MATERIALS AND METHODS}

In this randomized clinical trial, the participants were all the patients with non-ulcer dyspepsia who were referred to the outpatient gastrointestinal (GI) clinic of Ahvaz Imam Hospital, which is a referral center, during a 6-month period and were diagnosed as having $H$. pylori infection. The age range of the participants was 18-65 years and after explanation about the trial, all of them were requested to sign an informed consent.

Inclusion criteria were confirmation of $H$. pylori infection by two methods (urea breath test [UBT], stool Ag test, Rapid Urease Test(RUT), and or biopsy specimen), absence of history of $\mathrm{H}$. pylori eradication, and negative history for gastric malignancy. The exclusion criteria were recent use (within 4 weeks) of any of the medications used in the treatment of $H$. pylori eradication such as amoxicillin, clarithromycin and/or metronidazole, undergoing endoscopy for acute GI bleeding, and report of peptic ulcer, allergy to any of the medications used in H. pylori eradication, any history of esophageal varices, or undergoing endoscopy for esophageal band ligation, pregnancy or breast feeding for women, warfarin or clopidogrel consumption, history of any upper GI surgery other than Nissen Fundoplication, history of any comorbidity that precludes safe participation in the study such as sever renal or hepatic failure, heart failure, or pulmonary insufficiency.

Those who expressed an interest in participating and gave signed, informed consent were requested to complete an interview regarding the socioeconomic characteristics, health history, and a detailed GI history. Randomization was performed by using a random number chart for allocation to one of the treatment groups. The participants were randomly allocated to receive either 10-day sequential therapy with pantoprazole ( $40 \mathrm{mg}$ twice daily) plus amoxicillin ( 1 gr twice daily) for the first 5 days, followed by (pantoprazole $40 \mathrm{mg}$ twice daily plus levofloxacin $(500 \mathrm{mg}$ ) and tinidazole $(500 \mathrm{mg})$ twice daily for the remaining 5 days or 14-day quadruple therapy (pantoprazole $40 \mathrm{mg}$, clarithromycin $500 \mathrm{mg}$, bismuth sub citrate 240 $\mathrm{mg}$, and amoxicillin $1 \mathrm{gr}$ twice daily). This clinical trial has been registered as IRCT20160423027551N1.

\section{RESULTS}

Overall of 203 patients, 47 patients were excluded (34 patients in group PATT and 13 patients in group PACB, figure 1) and 156 patients were referred for final analysis. Age range of the participants was 18-65 years (average 36.9 years) and $50 \%$ of them (78 patients) were men. 78 patients were allocated to group A (10 days sequential therapy) and 78 patients grouped as B (traditional qua- 


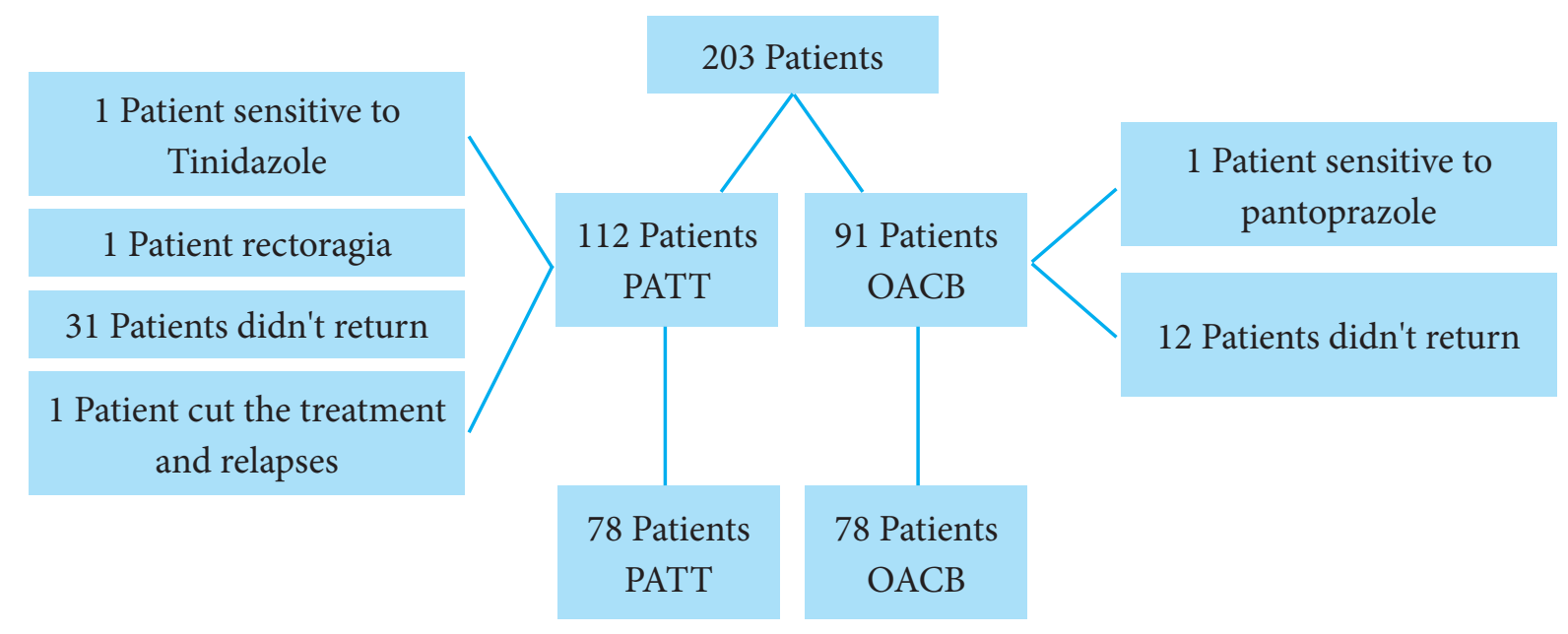

Fig.1: Algorithm of study

Table 1: Comparison of eradication rate between PALT and PACB groups

\begin{tabular}{lccc}
\hline Method & UBT Negative & UBT Positive & \multirow{P}{*}{$\boldsymbol{P}$ value } \\
\cline { 1 - 3 } PATT & $61(78.2 \%)$ & $17(21.7 \%)$ & \multirow{2}{*}{0.42} \\
\cline { 1 - 3 } PACB & $65(83.33 \%)$ & $13(16.6 \%)$ & \\
\hline
\end{tabular}

druple therapy). After completion of antibiotic course, all of the patients were followed up to receive 4 weeks acid suppression with PPI and then the eradication was confirmed by UBT. The demographic characteristics of the two groups were similar. During therapy there was not any major complication but in group A (sequential therapy), two patients complained of minor complications including musculoskeletal pain though they completed the course of trial. None of the patients in group B had any complaint or side effect.

In intention to treat (ITT) analysis, the rate of eradication in groups A and B were $54.4 \%$ and $71.4 \%$, respectively $(p=0.013)$, which proved the results in favor of clarithromycin base quadruple therapy while in per protocol analysis (PP), the rate of $H$. pylori eradication in group A was $78.2 \%$ (61 patients) while this rate in group B was $83.3 \%$ (65 patients) (table 1$)$ with no significant difference between the two groups ( $p=0.42$ ). In subgroup analysis, the rate of eradication among men in group A and B were $76.9 \%$ and $89.7 \%$, respectively $(p=0.22)$ while the eradication rate among women were $79.4 \%$ and $76.9 \%$, respectively $(p=1.00)$ (table 2$)$.
Table 2: Comparison of eradication rate between PALT and PACB groups according to sex

\begin{tabular}{lcccccc}
\hline \multirow{2}{*}{ SEX } & \multicolumn{2}{c}{ PACB } & \multicolumn{2}{c}{ PALT } & \\
\cline { 2 - 5 } & $\begin{array}{c}\text { UBT } \\
\text { positive }\end{array}$ & $\begin{array}{c}\text { UBT } \\
\text { negative }\end{array}$ & & $\begin{array}{c}\text { UBT } \\
\text { negative }\end{array}$ & $\begin{array}{c}\text { UBT } \\
\text { positive }\end{array}$ & P value \\
\hline Male & $4(10.3 \%)$ & $35(89.7 \%)$ & $30(76.9 \%)$ & $9(23.1 \%)$ & 0.22 \\
\hline Female & $9(23.1 \%)$ & $30(76.9 \%)$ & $31(79.48 \%)$ & $8(20.52 \%)$ & 1.00 \\
\hline
\end{tabular}

\section{DISCUSSION}

Because of the wide variety of $H$. pylori infection complications, the effective eradication of this bacterium is immensely important in clinical practice and with widespread consumption of antibiotics in developing countries, antibiotic resistance and treatment failure is a great challenge in this regard. In early $90 \mathrm{~s}$, the eradication rate with standard triple therapy has been reported to be around $80 \%$ while the rate and pattern of bacterial resistance is an ever changing issue and in most recent studies, this eradication rate declined to $45-60 \%$, which even further highlights the importance of determining the regional patterns of antibiotic resistance for better regimen selection. ${ }^{28}$

On the other hand, the side effects of antibiotics further encouraged researchers and clinicians to seek for even shorter courses of effective regimens with fewer antibiotics. One of the tempting patterns in this field was sequential therapy, which was introduced since $2000 .{ }^{40,41}$ In the current study that was performed in southwest Iran, we compared the sequential 10-day levofloxacin based therapy 
with traditional quadruple 2 weeks course of eradication regimen, which has been recommended as standard of care and the first line regimen by Iranian Association of Gastroenterology \& Hepatology (IAGH) ${ }^{42}$ The resistance rate of $H$. pylori against clarithromycin in Ahvaz city has been reported to be $24 \%$, which make this region having a high resistance rate. ${ }^{43}$

The findings of this study ( $78.2 \%$ eradication rate by levofloxacin base sequential therapy) was in contrast to a similar study by Alirezaei and colleagues ${ }^{44}$ who reported the sequential regimen efficacy to be higher than traditional therapy and also to Bilardi and co-workers who achieved better results with levofloxacin in comparison with quadruple therapy. ${ }^{45}$ These differences could be explained by the regional patterns of bacterial resistance and popularity of specific antibiotic prescription in any defined region. ${ }^{42,46,47}$

The complications and side effects of levofloxacin based regimen specially musculoskeletal pain were more than quadruple standard regimen though non-significant $(p=0.15)$ and similar to a multicentric Spanish study on 300 cases which reported minor complications such as nausea and myalgia in up to $20 \%$ of cases without any major side effect and these complications were explained to be resulted from the high dose of levofloxacin. ${ }^{48} \mathrm{Har}-$ mandar and others in 2016 evaluated clarithromycin base sequential therapy for $H$. pylori eradication but the advantages of this regimen were also non-significant. ${ }^{40}$

A Taiwanese study in 2015 suggested that the efficacies of sequential 10 days and triple 14 days regimens varied according to the prevalence of clarithromycin and metronidazole resistance and neither sequential 10-day nor triple 14-day protocols achieved acceptable eradication rates in regions with high clarithromycin or high metronidazole resistance, and could not be recommended in such settings. ${ }^{49}$

In 2015, Masjedizadeh and colleagues reported the standard clarithromycin-base triple therapy to be the most effective regimen for eradication of $H$. pylori infection in Ahvaz despite heterogeneous reports about the resistance of $H$. pylori strains to clarithromycin in Iran and the record of a high rate of resistance to clarithromycin in Ahvaz, ${ }^{50}$ which could be considered as further evidence to support the findings of the current study and in contrast to an Italian study that reported in an area with $>15 \%$ prevalence of clarithromycin resistant, a levofloxacin-containing sequential therapy could be more effective, equally safe, and cost-saving compared with a clarithromycin-containing sequential therapy. ${ }^{51}$

Similarity of these protocols has been also confirmed by previous extended clinical trial in Ahvaz city in 2014, which evaluated 295 patients and suggested sequential therapy as an acceptable substitute for standard quadruple therapy but was unable to find any superiority for sequential therapy. ${ }^{52}$

Based on the current findings and in support of previous data, the only important benefit of sequential therapy could be lower cost and shorter course of treatment, which could be an important issue especially among developing countries. Having considered the limited sources of insurance support and health refund, it is still valuable to seek for more effective short courses of $H$. pylori eradication regimens.

\section{CONCLUSION}

It seems that current levofloxacin-base sequential therapy does not have any advantage in comparison with quadruple regimen and until finding any more effective short-course therapy for $H$. pylori eradication, we still encourage the previous quadruple regimen to be used as the first-line therapy.

\section{ETHICAL APPROVAL}

There is nothing to be declared.

\section{CONFLICT OF INTEREST}

The authors declare no conflict of interest related to this work.

\section{REFERENCES}

1. Cammarota G, Tursi A, Montalto T, Papa A, Veneto G, Trua F, et al. Clinical assessment of the relationship of Helicobacter pylori to gastroduodenal pathologies. A prospective analysis of 253 consecutive patients. Panminerva medica 1995;37:178-81.

2. Ben RA, Kchir N, Bouali MR, Ebdelli N, Fsili R, Khediri F, et al. Gastric MALT lymphoma. A clinico-pathological study of 65 cases. Relationship to Helicobacter pylori. Tunis Med 2000;78:484-93.

3. Compare D, Rocco A, Nardone G. Risk factors in gastric cancer. Eur Rev Med Pharmacol Sci 2010;14:302-8. 
4. Burkitt MD, Duckworth CA, Williams JM, Pritchard DM. Helicobacter pylori-induced gastric pathology: insights from in vivo and ex vivo models. Dis Model Mech 2017;10:89-104. doi:10.1242/dmm.027649.

5. Wang F, Meng W, Wang B, Qiao L. Helicobacter pyloriinduced gastric inflammation and gastric cancer. Cancer Lett 2014;345:196-202. doi:10.1016/j.canlet.2013.08.016.

6. Masjedizadeh AR, Fathizadeh P, Shayesteh AA, Alavinejad P, Hashemi J, Hajiani E. Prevalence of $H$. pylori Infection and Precancerous Gastric Lesion in Family Relative of Gastric Cancer in South West of Iran. Gastroenterol Hepatol Res J 2013;2:878-82.

7. Cammarota G, Ianiro G, Bibbò S, Di Rienzo TA, Masucci L, Sanguinetti M, et al. Culture-guided treatment approach for Helicobacter pylori infection: review of the literature. World J Gastroenterol 2014;20:5205-11. doi: 10.3748/wjg.v20.i18.5205.

8. Malfertheiner P, Selgrad M. Management of $H$. pylori Infection in Europe. H. pylori Res 2016:491-502. doi:10.1007/978-4-431-55936-8_21.

9. Papastergiou V, Georgopoulos SD, Karatapanis S. Treatment of Helicobacter pylori infection: Past, present and future. World J Gastrointest Pathophysiol 2014;5:392-9. doi:10.4291/wjgp.v5.i4.392.

10. Karamanolis GP, Daikos GL, Xouris D, Goukos D, Delladetsima I, Ladas SD. The evolution of Helicobacter pylori antibiotics resistance over 10 years in Greece. Digestion 2014;90:229-31. doi:10.1159/000369898.

11. Zhu R, Chen K, Zheng YY, Zhang HW, Wang JS, Xia YJ, et al. Meta-analysis of the efficacy of probiotics in Helicobacter pylori eradication therapy. World J Gastroenterol 2014;20:18013-21. doi:10.3748/wjg.v20.i47.18013.

12. Megraud F, Coenen S, Versporten A, Kist M, LopezBrea M, Hirschl AM, et al. Helicobacter pylori resistance to antibiotics in Europe and its relationship to antibiotic consumption. Gut 2013;62:34-42. doi:10.1136/ gutjnl-2012-302254.

13. Della Monica P, Lavagna A, Masoero G, Lombardo L, Crocella L, Pera A. Effectiveness of Helicobacter pylori eradication treatments in a primary care setting in Italy. Aliment Pharmacol Ther 2002;16:1269-75. doi:10.1046/ j.1365-2036.2002.01244.x.

14. Zullo A, De Francesco V, Hassan C, Morini S, Vaira D. The sequential therapy regimen for Helicobacter pylori eradication: a pooled-data analysis. Gut 2007;56:1353-7. doi:10.1136/gut.2007.125658.

15. Tursi A, Elisei W, Giorgetti G, Picchio M, Brandimarte G. Efficacy, tolerability, and factors affecting the efficacy of the sequential therapy in curing Helicobacter pylori infection in clinical setting. J Investig Med 2011;59:917-20. doi:10.2310/JIM.0b013e318217605f.
16. Urgesi R, Pelecca G, Cianci R, Masini A, Zampaletta C, Riccioni ME, et al. Helicobacter pylori infection: is sequential therapy superior to standard triple therapy? A single-centre Italian study in treatment-naive and non-treatment-naive patients. Can J Gastroenterol 2011;25:315-8. doi:10.1155/967671/2011.

17. Mahachai V, Sirimontaporn N, Tumwasorn S, ThongNgam D, Vilaichone RK. Sequential therapy in clarithromycin-sensitive and resistant Helicobacter pylori based on polymerase chain reaction molecular test. J Gastroenterol Hepatol 2011;26:825-8. doi:10.1111/j.14401746.2011.06660.x.

18. Masjedizadeh AR, Hajiani E, Jalal Hashemi S, Alavinejad P, Dalvand H. Sequential Therapy vs Quadruple Therapy for Helicobacter pylori Eradication in South West of Iran. Euroasian J Hepatogastroenterol 2014;4:63-6. doi:10.5005/jp-journals-10018-1103.

19. Caselli M, Zullo A, Maconi G, Parente F, Alvisi V, Casetti T, et al. "Cervia II Working Group Report 2006": guidelines on diagnosis and treatment of Helicobacter pylori infection in Italy. Dig Liver Dis 2007;39:782-9. doi:10.1016/j.dld.2007.05.016.

20. Rokkas T, Sechopoulos P, Robotis I, Margantinis G, Pistiolas D. Cumulative H. pylori eradication rates in clinical practice by adopting first and second-line regimens proposed by the Maastricht III consensus and a third-line empirical regimen. Am J Gastroenterol 2009;104:21-5. doi:10.1038/ajg.2008.87.

21. Gatta L, Vakil N, Leandro G, Di Mario F, Vaira D. Sequential therapy or triple therapy for Helicobacter pylori infection: systematic review and meta-analysis of randomized controlled trials in adults and children. Am J Gastroenterol 2009;104:3069-79. doi:10.1038/ajg.2009.555.

22. Fock KM, Katelaris P, Sugano K, Ang TL, Hunt R, Talley NJ, et al. Second Asia-Pacific consensus guidelines for helicobacter pylori infection. $J$ Gastroenterol Hepatol 2009;24:1587-600. doi:10.1111/j.1440-1746.2009.05982.x.

23. Graham DY, Fischbach L. Helicobacter pylori treatment in the era of increasing antibiotic resistance. Gut 2010;59:1143-53. doi:10.1136/gut.2009.192757.

24. Gisbert JP. Rescue" regimens after Helicobacter pylori treatment failure. World J Gastroenterol 2008;14:5385402. doi:10.3748/wjg.14.5385.

25. Gisbert JP, Perez-Aisa A, Bermejo F, Castro-Fernandez M, Almela P, Barrio J, et al. Second-line therapy with levofloxacin after failure of treatment to eradicate helicobacter pylori infection: time trends in a Spanish Multicenter Study of 1000 patients. J Clin Gastroenterol 2013;47:1305. doi:10.1097/MCG.0b013e318254ebdd.

26. Noh HM, Hong SJ, Han JP, Park KW, Lee YN, Lee TH, et al. Eradication Rate by Duration of Third-line Rescue 
Therapy with Levofloxacin after Helicobacter pylori Treatment Failure in Clinical Practice. Korean J Gastroenterol 2016;68:260-4. doi:10.4166/kjg.2016.68.5.260.

27. Cao Z, Chen Q, Zhang W, Liang X, Liao J, Liu W, et al. Fourteen-day optimized levofloxacin-based therapy versus classical quadruple therapy for Helicobacter pylori treatment failures: a randomized clinical trial. Scand $J$ Gastroenterol 2015;50:1185-90. doi:10.3109/00365521. 2015.1037345 .

28. Tai WC, Lee CH, Chiou SS, Kuo CM, Kuo CH, Liang CM, et al. The clinical and bacteriological factors for optimal levofloxacin-containing triple therapy in second-line $\mathrm{He}$ licobacter pylori eradication. PLoS One 2014;9:e105822. doi:10.1371/journal.pone.0105822.

29. Paoluzi OA, Del Vecchio Blanco G, Visconti E, Coppola M, Fontana C, Favaro M, et al. Low efficacy of levofloxacin-doxycycline-based third-line triple therapy for Helicobacter pylori eradication in Italy. World J Gastroenterol 2015;21:6698-705. doi:10.3748/wjg.v21.i21.6698.

30. Haji-Aghamohammadi AA, Bastani A, Miroliaee A, Oveisi $\mathrm{S}$, Safarnezhad S. Comparison of levofloxacin versus clarithromycin efficacy in the eradication of Helicobacter pylori infection. Caspian J Intern Med 2016;7:267-71.

31. Kohanteb J, Bazargani A, Saberi-Firoozi M, Mobasser A. Antimicrobial susceptibility testing of Helicobacter pylori to selected agents by agar dilution method in Shiraz-Iran. Indian J Med Microbiol 2007;25:374-7.

32. Mokhtare M, Hosseini V, Tirgar Fakheri H, Maleki I, Taghvaei T, Valizadeh SM, et al. Comparison of quadruple and triple Furazolidone containing regimens on eradication of helicobacter pylori. Med J Islam Repub Iran 2015;29:195.

33. Siavoshi F, Saniee P, Latifi-Navid S, Massarrat S, Sheykholeslami A. Increase in resistance rates of $H$. pylori isolates to metronidazole and tetracycline-comparison of three 3-year studies. Arch Iran Med 2010;13:177-87.

34. Shokrzadeh L, Jafari F, Dabiri H, Baghaei K, Zojaji H, Alizadeh AH, et al. Antibiotic susceptibility profile of Helicobacter pylori isolated from the dyspepsia patients in Tehran, Iran. Saudi J Gastroenterol 2011;17:261-4. doi:10.4103/1319-3767.82581.

35. Abadi AT, Taghvaei T, Mobarez AM, Carpenter BM, Merrell DS. Frequency of antibiotic resistance in Helicobacter pylori strains isolated from the northern population of Iran. J Microbiol 2011;49:987-93. doi:10.1007/s12275011-1170-6.

36. Talebi Bezmin Abadi A, Ghasemzadeh A, Taghvaei T, Mobarez AM. Primary resistance of Helicobacter pylori to levofloxacin and moxifloxacine in Iran. Intern Emerg Med 2012;7:447-52. doi:10.1007/s11739-011-0563-1.

37. Khademi F, Poursina F, Hosseini E, Akbari M, Safaei HG. Helicobacter pylori in Iran: A systematic review on the antibiotic resistance. Iran J Basic Med Sci 2015;18:2-7.

38. Chuah SK, Liang CM, Lee CH, Chiou SS, Chiu YC, Hu $\mathrm{ML}$, et al. A randomized control trial comparing 2 levofloxacin-containing second-line therapies for Helicobacter pylori eradication. Medicine (Baltimore) 2016;95:e3586. doi:10.1097/MD.0000000000003586.

39. Shaikh T, Fallone CA. Effectiveness of Second through Sixth Line Salvage Helicobacter pylori Treatment: Bismuth Quadruple Therapy is Almost Always a Reasonable Choice. Can J Gastroenterol Hepatol 2016;2016:7321574. doi:10.1155/2016/7321574.

40. Harmandar F, İlikhan SU, Üstündağ Y, Harmandar O. The efficacy of sequential therapy in eradication of Helicobacter pylori in Turkey. Niger J Clin Pract 2017;20:61621. doi:10.4103/1119-3077.196991.

41. Vaira D, Zullo A, Hassan C, Fiorini G, Vakil N. Sequential therapy for Helicobacter pylori eradication: the time is now! Ther Adv Gastroenterol 2009;2:317-22. doi: $10.1177 / 1756283$ X09343326.

42. Fakheri H, Saberi Firoozi M, Bari Z. Eradication of Helicobacter Pylori in Iran: A Review. Middle East J Dig Dis 2018;10:5-17. doi:10.15171/mejdd.2017.84.

43. Moosavian M, Tajbakhsh S, Samarbaf-Zadeh AR. Rapid detection of clarithromycin-resistant Helicobacter pylori in patients with dyspepsia by fluorescent in situ hybridization (FISH) compared with the E-test. Ann Saudi Med 2007;27:84-8. doi:10.5144/0256-4947.2007.84.

44. Alirezaei A, Jamshidi Fard A, Argani H, Talaie R, Nooraninia S, Iranshahi M, et al. Helicobacter pylori Eradication With Levofloxacin or Clarithromycin in Dialysis versus Nonuremic Patients. Iran J Kidney Dis 2017;11:237-40.

45. Bilardi C, Dulbecco P, Zentilin P, Reglioni S, Iiritano E, Parodi A, et al. A 10-day levofloxacin- based therapy in patients with resistant Helicobacter pylori infection: a controlled trial. Clin Gastroenterol Hepatol 2004;2:9971002. doi:10.1016/S1542-3565(04)00458-6.

46. Massarrat $\mathrm{S}$, Sheykholeslami A. Increase in resistance rates of $H$. pylori isolates to metronidazole and tetracycline-comparison of three 3-year studies. Arch Iran Med 2010;13:177-87.

47. Khashei R, Dara M, Bazargani A, Bagheri Lankarani K, Taghavi A, Moeini M, et al. High rate of A2142G point mutation associated with clarithromycin resistance among Iranian Helicobacter pylori clinical isolates. APMIS 2016;124:787-93. doi:10.1111/apm.12567.

48. Gisbert JP, Bermejo F, Castro-Fernández M, Pérez-Aisa A, Fernández-Bermejo M, Tomas A, et al. Second-line rescue therapy with levofloxacin after $H$. pylori treatment failure: a Spanish multicenter study of 300 patients. Am J Gastroenterol 2008;103:71-6. doi:10.1111/j.15720241.2007.01500.x. 
49. Liou JM, Chen CC, Chang CY, Chen MJ, Chen CC, Fang YJ,et al. Sequential therapy for 10 days versus triple therapy for 14 days in the eradication of Helicobacter pylori in the community and hospital populations: a randomised trial. Gut 2016;65:1784-92. doi:10.1136/ gutjnl-2015-310142.

50. Masjedizadeh A, Zaeemzadeh N, Mard SA, Vanani GS. Comparing the efficacy of four different protocols for eradicating of Helicobacter pylori infection in Ahvaz, southwest Iran. Prz Gastroenterol 2015;10:94-9. doi:10.5114/pg.2015.49001.

51. Romano M, Cuomo A, Gravina AG, Miranda A, Iovene MR, Tiso A, et al. Empirical levofloxacin-containing versus clarithromycin-containing sequential therapy for Helicobacter pylori eradication: a randomised trial. Gut 2010;59:1465-70. doi:10.1136/gut.2010.215350.

52. Masjedizadeh AR, Hajiani E, Hashemi SJ, Alavinejad P, Dalvand H. Sequential Therapy VS. Quadruple Therapy For Helicobacter Pylori Eradication in South West of Iran. Euroasian J HepatoGastroenterol 2014;4:63-6. doi:10.5005/jp-journals-10018-1103. 